\title{
Spreadsheet solution for the computation of the mean wind speed and turbulence intensity profiles according to the Romanian standard
}

\author{
Elena-Alexandra Chiulan ${ }^{1, *}$, Andrei-Mugur Georgescu ${ }^{1}$, Costin-Ioan Coșoiu ${ }^{1}$, and Anton Anton ${ }^{1}$ \\ ${ }^{1}$ Technical University of Civil Engineering Bucharest, Hydraulic and Environmental Protection Department, Lacul Tei Bvd., no. $122-$ \\ 124, RO 020396, Bucharest, Romania
}

\begin{abstract}
The presented paper focuses on the computation of the mean wind speed and turbulence intensity profiles for all the cities from Romania. The calculation of both, the mean wind speed profile and the turbulence intensity profile, had as mathematical support the equations presented in the Romanian design standard for wind action CR 1-1-4/2012. The main objective of this paper was to provide a tool for the computation of the two wind action features. This method was based on creating a spreadsheet in Excel with which, in just a few seconds, a user could correctly obtain the two wind characteristics. This Excel dashboard can be used as a teaching material for students as well as input data for structural design engineers in the process of modelling and observing the behaviour of a building excited by wind action on a particular city in Romania.
\end{abstract}

\section{Introduction}

Since increasingly tall buildings have been built around the world, over the last two decades a growing interest has begun to be given to the behaviour of these structures under the influence of the wind $[1 \div 14]$. Moreover, increased attention has also been paid to wind action on conventional structures (height less than 200 meters) and how these buildings interact and influence the structures in their vicinity under the turbulent wind action $[1 \div 14]$. Thus, building design standards for wind action have been developed for different areas around the Globe. From the most important design codes for wind action can be remained those developed for America [15], Europe [16], Australia [17], China [18], Japan [19], Korea [20]. In these standards, important information is provided both in terms of dynamic wind pressure through zoning maps made for a given country, terrain categories in a certain country depending on the variable roughness level etc., as well as, calculation methods by which can be determined the wind reference values, the mean wind speed and turbulence intensity profiles with which the atmospheric boundary layer can be characterized for a certain location in a country.

For Romania, in 2012 the CR 1-1-4/2012 "Design code. Evaluation of wind action on constructions" [21] was developed. This standard was created based on the already existing prescriptions in the specific European standard [16]. But, for this code, were considered the parameters that characterize the surface of Romania (dynamic pressure, terrain categories etc.).

The main objective of our work was to determine the profiles of the mean wind speed and the profiles of turbulence intensity for each city on the territory of Romania by an automatic calculation method. To achieve our goal, the Excel program was used as a calculation tool. Thus, we could create a spreadsheet in which the values that are characteristic of each city in Romania were introduced. By using the mathematical model provided in CR 1-1-4/2012 [21], we were able to determine the two wind characteristics mentioned above (mean wind speed and turbulence intensity profiles).

Due to the growing need for knowledge of wind action on structures, this dashboard in Excel can be of great help not only for civil engineering students, but also for engineers involved in the design process of structures. For example, parameters obtained using this calculation method can be used as input data in any FEM or CFD software to more accurate representation based on code provisions of the wind action for a location in Romania.

Another very import reason for making this spreadsheet was that in any design standard there is the specification that for any structure exceeding 200 meters, special studies are required to characterize its response to wind action [21]. These special studies consist of carrying out experimental tests on models that reproduce the real-scale structures in a wind tunnel. In Romania, there are several wind tunnels where experimental tests can be made. For instance, at the Aerodynamics and Wind Engineering Laboratory "Constantin Iamandi" from the Technical University of Civil Engineering Bucharest there are four wind tunnels where several wind action problems can be studied $[2 \div 3]$, [14]. The most important of the four tunnels is the TASL1-M tunnel, which was refurbished in 2015 , is equipped with

* Corresponding author: alexandra.chiulan@hidraulica.utcb.ro 
a variable roughness system and has a $250-\mathrm{kW}$ axial fan. TASL1-M can simulate the atmospheric boundary layer of a site (in terms of mean wind speed and turbulence intensity profiles) according to Eurocode [2] and CR 1$1-4 / 2012$ [21]. By using this spreadsheet in Excel, we will be able to know exactly which mean wind speed and turbulence intensity profile will best fit the experimental tests made in the wind tunnel for a specific location. This is possible by comparing the profiles obtained from the wind tunnel calibration experimental measurements and the data provided by using this automatic method achieved based on CR 1-1-4/2012 formulas.

In the first part of the paper, the CR 1-1-4/2012 mathematical formulas used to obtain the mean wind speed and turbulence intensity profiles are described. The second part details the most important steps to be followed in the spreadsheet. In the third part are presented and discussed the main results obtained through the proposed Excel spreadsheet. The final part of this paper shows which are the most important concluding remarks of our work.

\section{The CR 1-1-4/2012 mathematical support}

In the process of achieving the mean wind speed and turbulence intensity profiles characteristic for Romania, the mathematical formulas presented in CR 1-1-4/2012 [16], [21] were used. In the following sections will be detailed the equations that were the basis of the spreadsheet for the computation of the two desired profiles which describe the atmospheric boundary layer of a location. Also, these formulas will be explained in the order of appearance in the dashboard.

\subsection{Reference values of wind speed and dynamic pressure}

According to CR 1-1-4/2012, the wind speed reference value, $v_{b}$, is defined as the characteristic wind speed averaged over 10 minutes, determined at a height of 10 meters, independent of the wind direction, in open field and having $2 \%$ probability of exceedance in one year [16], [21]. Through a brief analysis of the mathematical formula by which the wind speed reference value, $v_{b}$, is defined, this is in relation to the reference value of the dynamic wind pressure, $q_{b}$. So, the relationship between the reference value of the wind speed and the dynamic pressure reference value is the following [16], [21]:

$$
q_{b}=\frac{1}{2} \rho \cdot v_{b}^{2} \Rightarrow q_{b}=0.625 \cdot v_{b}^{2} \Rightarrow v_{b}=\sqrt{1,6 \cdot q_{b}}
$$

where: $\rho$ is the air density (for air $\rho=1,25 \mathrm{~kg} / \mathrm{m}^{3}$ ), $q_{b}$ is the reference value of the dynamic wind pressure.

For Romania, the reference values of the dynamic wind pressure are presented in the zoning map existing in the Romanian design standard for wind action [21]. Fig. 1 shows the zoning map of the dynamic wind pressure reference values for the territory of Romania [21]. Based on the values presented in the map and using equation (1) we could determine the wind speed reference values specific for each site in Romania.

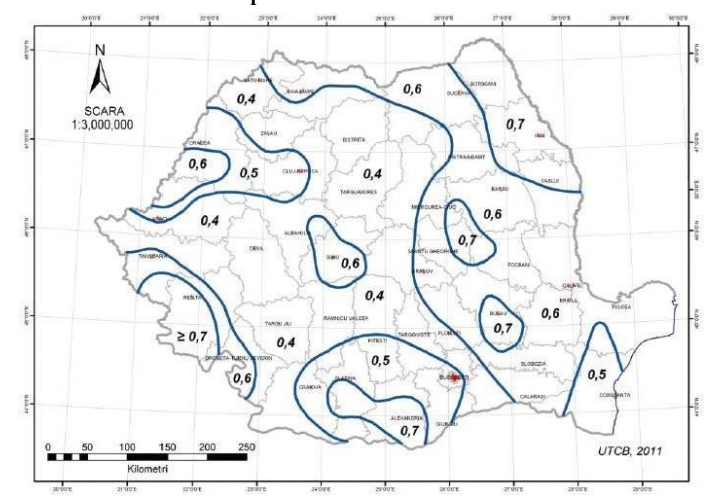

Fig. 1. Zoning map of the reference values of the dynamic wind pressure, $q_{b}$, according to CR 1-1-4/2012 [21].

\subsection{The mean wind speed profile}

From the literature it is well-known the fact that the mean wind speed profile with the height above the ground, produced by the surface roughness, is generally expressed by a law, such as power law (Davenport law) or logarithmic law. In the case of the Romanian code, the expression that describes the mean wind speed profile is expressed by the next logarithmic law [16], [21]:

$$
v_{m}(z)=\frac{v_{*}}{k} \cdot\left(\ln \frac{z}{z_{0}}\right)
$$

where: $v_{m}(z)$ is the mean wind speed at a height $z$ above the ground, $v_{*}$ is the shear velocity, $k$ is the von Kármán constant $(k=0,4), z$ is the height above the ground and $z_{0}$ is the roughness height [21].

An important feature of this logarithmic law is that it is valid throughout the entire atmospheric boundary layer, but its use is especially recommended for the first 200 meters of the terrain surface. So, by using this law, it can be accurately modelled around $10 \%$ of the atmospheric boundary layer [16], [21].

In accordance with CR 1-1-4/2012, the mean wind speed, $v_{m}(z)$, at a height $z$ above the ground depends on the roughness of the terrain and the reference value of wind speed. The code provides for the computation of the mean wind speed a formula which is equivalent to equation (2), as follows [16], [21]:

$$
v_{m}(z)=c_{r}(z) \cdot v_{b}
$$

where: $c_{r}(z)$ is the roughness factor for wind speed.

The wind speed roughness factor, $c_{r}(z)$, is defined as the one that models the variation of the mean wind speed with height $z$ above the ground for each of the terrain categories according to the wind speed. This factor is expressed by [16], [21]: 


$$
c_{r}(z)=\left\{\begin{array}{l}
k_{r}\left(z_{0}\right) \cdot \ln \left(\frac{z}{z_{0}}\right), z_{\min }<z \leq z_{\max }=200 m \\
c_{r}\left(z=z_{\min }\right), z \leq z_{\min }
\end{array}\right.
$$

where: $k_{r}(z)$ is the terrain factor, the values of $z_{0}$ and $z_{\text {min }}$ are specified in the design code according to the terrain category.

In CR 1-1-4/2012 is presented the following table which describes the types of terrain roughness existing in Romania along with the roughness length, $z_{0}$, of each type of terrain [21], see Table 1.

Table 1. The values of the length of roughness, $z_{0}[\mathrm{~m}]$, according to CR 1-1-4/2012, for five different categories of terrain in Romania country [21].

\begin{tabular}{|c|l|c|c|}
\hline $\begin{array}{c}\text { Terrain } \\
\text { category }\end{array}$ & \multicolumn{1}{|c|}{ Description of the terrain } & $\begin{array}{c}\mathbf{z} 0, \\
\mathbf{m}\end{array}$ & $\begin{array}{c}\mathbf{Z} \mathbf{m i n}, \\
\mathbf{m}\end{array}$ \\
\hline 0 & $\begin{array}{l}\text { Sea or costal areas exposed to } \\
\text { the winds coming from the sea }\end{array}$ & 0,003 & 1 \\
\hline I & $\begin{array}{l}\text { Lakes or flat and horizontal } \\
\text { terrains with negligible and } \\
\text { unobstructed vegetation }\end{array}$ & 0,01 & 1 \\
\hline II & $\begin{array}{l}\text { Open field - terrain with grass } \\
\text { and/ or isolated obstacles (trees, } \\
\text { buildings) at least 20 times the } \\
\text { height of the obstacle }\end{array}$ & 0,05 & 2 \\
\hline III & $\begin{array}{l}\text { Areas uniformly covered with } \\
\text { vegetation or with buildings and } \\
\text { with isolated obstacles at } \\
\text { distances of up to 20 times the } \\
\text { height of the obstacle (e.g. } \\
\text { villages, suburban terrain, } \\
\text { forests) }\end{array}$ & 0,3 & 5 \\
\hline IV & $\begin{array}{l}\text { Areas where at least } 15 \% \text { of the } \\
\text { area is covered with buildings } \\
\text { with a height of more than 15 m } \\
\text { (e.g. urban areas) }\end{array}$ & 1,0 & 10 \\
\hline
\end{tabular}

The expression that gives the value of the terrain factor is the following [16], [21]:

$$
k_{r}\left(z_{0}\right)=0,189 \cdot\left(\frac{z_{0}}{0,05}\right)^{0,07}
$$

where: $k_{r}\left(z_{0}\right)$ is the terrain factor.

If the value of the roughness length, $z_{0}$, in equation (5) is replaced with the given value of $z_{0}$ from Table 1, the value of the terrain factor is obtained for each of the five different terrain categories. To simplify the calculation, the Romanian standard provides the already calculated values of the terrain factor, as can be seen in Table 2 [21].

Table 2. The values of the $k_{r}\left(z_{0}\right)$ in accordance to CR 1-1$4 / 2012$, for the categories of terrain in Romania [21].

\begin{tabular}{|c|c|c|c|c|c|}
\hline $\begin{array}{c}\text { Terrain } \\
\text { category }\end{array}$ & $\mathbf{0}$ & I & II & III & IV \\
\hline$k_{r}\left(z_{0}\right)$ & 0,155 & 0,169 & 0,189 & 0,214 & 0,233 \\
\hline
\end{tabular}

By computing the previously presented equations (3) $\div(5)$ one can obtain not only the mean wind speed value for a specified height $z$, but also the mean wind speed profile characteristic for a certain location in Romania.

\subsection{The turbulence intensity profile}

By definition, the turbulence intensity of wind, $I_{v}(z)$, characterizes the fluctuations in the instantaneous wind speed around the mean value [16], [21]. The Romanian code CR 1-1-4/2012 defines the turbulence intensity at the height $z$ above the ground as the ration between the standard deviation of the instantaneous wind speed fluctuations, $\sigma_{v}$, and the mean wind speed at the height $z, v_{m}(z)$, with the following formula [16], [21]:

$$
I_{v}(z)=\left(\frac{\sigma_{v}}{v_{m}(z)}\right)
$$

where: $\sigma_{v}$ is standard deviation of the instantaneous wind speed fluctuations, $v_{m}(z)$ is the mean wind speed at the height $z$.

To simplify the calculation of the wind turbulence intensity $z$, the next equivalent equation is prescribed in the code [16], [21]:

$$
I_{v}(z)=\left\{\begin{array}{l}
\frac{\sqrt{\beta}}{2,5 \cdot \ln \left(\frac{z}{z_{0}}\right)}, z_{\text {min }}<z \leq z_{\max }=200 m \\
I_{v}\left(z=z_{\text {min }}\right), z \leq z_{\text {min }}
\end{array}\right.
$$

where: $\beta$ is the proportionality factor that varies with the roughness of the terrain surface.

Also, for the computation of the turbulence intensity of wind at a specific height $z$, the values of the proportionality factor can be considered simplified as being independent of the height $z$ above the ground. This fact is based on the following mathematical relationship [16], [21]:

$$
4,5 \leq \beta=4,5-0,856 \ln \left(z_{0}\right) \leq 7,5
$$

Furthermore, in the case of determining the proportionality factor, the code provides its already calculated values by introducing the specific roughness height (see Table 1) for different terrain categories. The values thus obtained are presented in the Table 3 [21]:

Table 3. The values of the proportionality factor $\sqrt{\beta}$ for the five different types of terrain in Romania [21].

\begin{tabular}{|c|c|c|c|c|c|}
\hline $\begin{array}{c}\text { Terrain } \\
\text { category }\end{array}$ & $\mathbf{0}$ & I & II & III & IV \\
\hline$\sqrt{\beta}$ & 2,74 & 2,74 & 2,66 & 2,35 & 2,12 \\
\hline
\end{tabular}

The turbulence intensity value of the wind for an imposed height $z$ can be computed by using the 
equation $(7) \div(8)$. By using the same mathematical formulas, the turbulence intensity profile for a specified city in Romania can be obtained.

\section{The computation of the mean wind speed and turbulence intensity profiles}

To be able to use this spreadsheet solution for our purpose, several important steps had to be followed. These main steps are represented in Fig. 2.
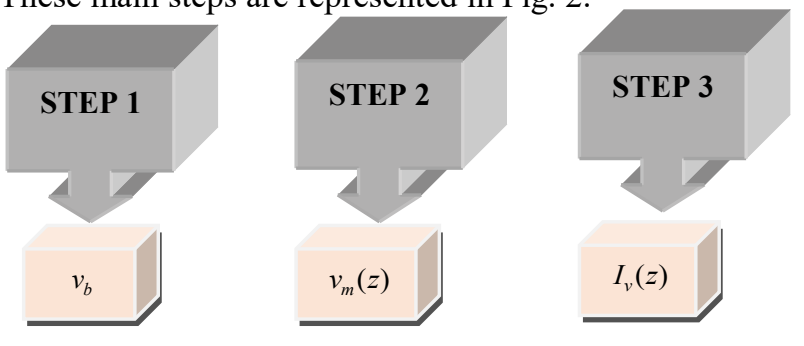

Fig. 2. The scheme of the main steps to be followed in the Excel spreadsheet solution.

The algorithms for calculating the three parameters mentioned in Fig. 2 will be further detailed.

For the first step, we considered as input parameters for the reference value of wind speed, $v_{b}$, the following characteristics for each location on the territory of Romania: the air density $\rho\left(\rho=1,25 \mathrm{~kg} / \mathrm{m}^{3}\right)$ and the reference value of the dynamic wind pressure, $q_{b}$, from the zoning map (see Fig. 1). With these values, the value of the reference wind speed, $v_{b}$, was computed according to equation (1). Fig. 3 presents the scheme of this algorithm.
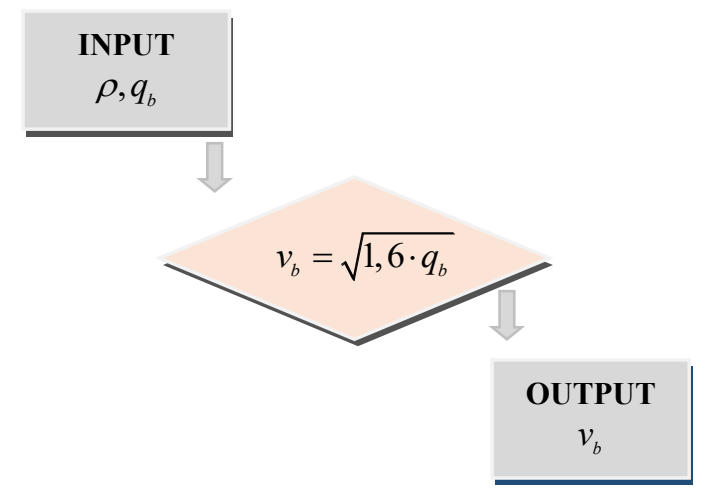

Fig. 3. The scheme of achieving the reference value of the wind speed, $v_{b}$, for a specific city in Romania.

As for the computation of the mean wind speed value at a specified height $z, v_{m}(z)$, according to equation (3), were taken into account the next parameters: the height above the ground were we wanted to calculate the mean wind speed, $z$, the reference value of the wind speed, $v_{b}$ (see Fig. 1 and Fig. 3) and the roughness factor for wind speed, $c_{r}(z)$, determined by equation (4). Also, to achieve the value of the roughness factor for wind speed, $c_{r}(z)$, we had to see in which category of terrain the studied city was (see Table 1). After that, we had to choose the values of roughness length, $z_{0}$, (see Table 1) and of the terrain factor, $k_{r}\left(z_{0}\right)$, (see Table 2).

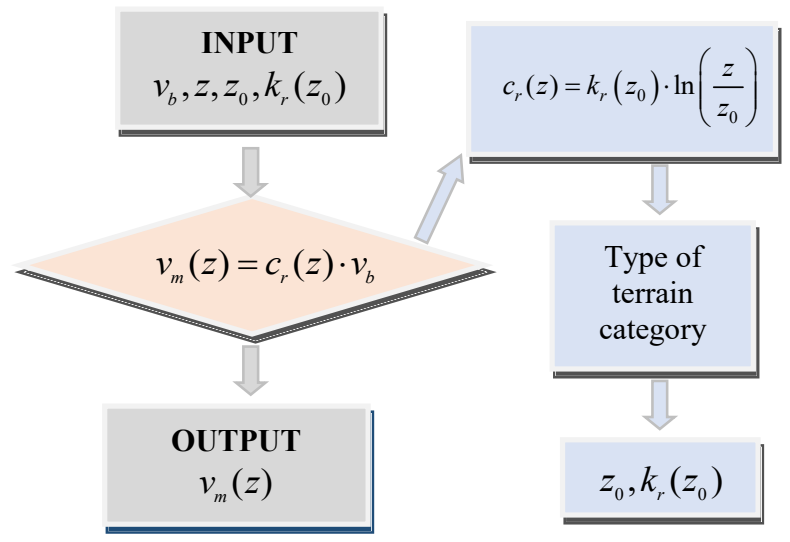

Fig. 4. The scheme of achieving the mean wind speed value at a specified height $\mathrm{z}, v_{m}(z)$.

In Fig. 4 is schematically shown the operation of achieving the mean wind speed value for a certain height $z$. Since the main purpose of this work was to determine the mean wind speed profile for each city from Romania, the algorithm had to be repeated several times for different heights $z$. Moreover, given the code specification that the logarithmic law which defines the mean wind speed profile is reliable for the first 200 meters from the terrain surface, the heights considered in the profile calculation were 201 values from 0 meters to 200 meters. Based on this procedure the mean wind speed profiles could be obtained throughout Romania.

In order to determine the turbulent intensity at a certain height $z, I_{v}(z)$, the following input data were entered into the spreadsheet: the height above the ground were we wanted to obtain the turbulent intensity, $z$, the value of roughness length, $z_{0}$, (see Table 1) and the value of the proportionality factor, $\sqrt{\beta}$, specific to the considered type of terrain (see Table 3). Fig. 5 highlights how turbulence intensity of wind, $I_{v}(z)$, can be obtained at a height $z$ for a considered site.

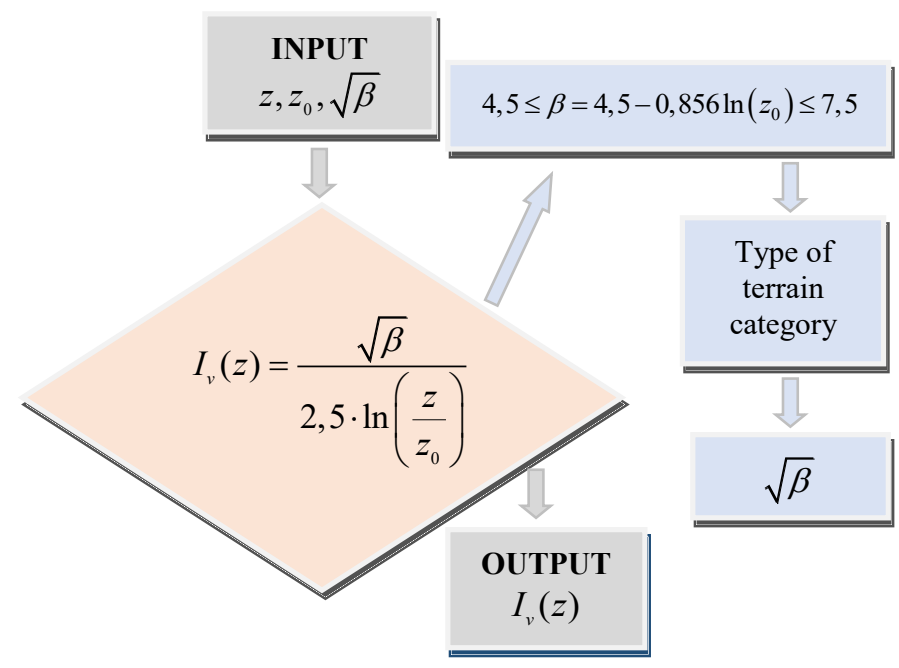

Fig. 5. The scheme of achieving the turbulence intensity value at specified height $\mathrm{z}, I_{v}(z)$. 
For achieving the wind turbulent intensity profile, we have also chosen 201 values from 0 meters to 200 meters and repeated the procedure exemplified in Fig. 5. Thus, we were able to obtain all turbulence intensity profiles for Romania.

Fig. 6 shows a capture of the spreadsheet created in Excel [22]. This spreadsheet was designed to meet all the previous detailed steps.
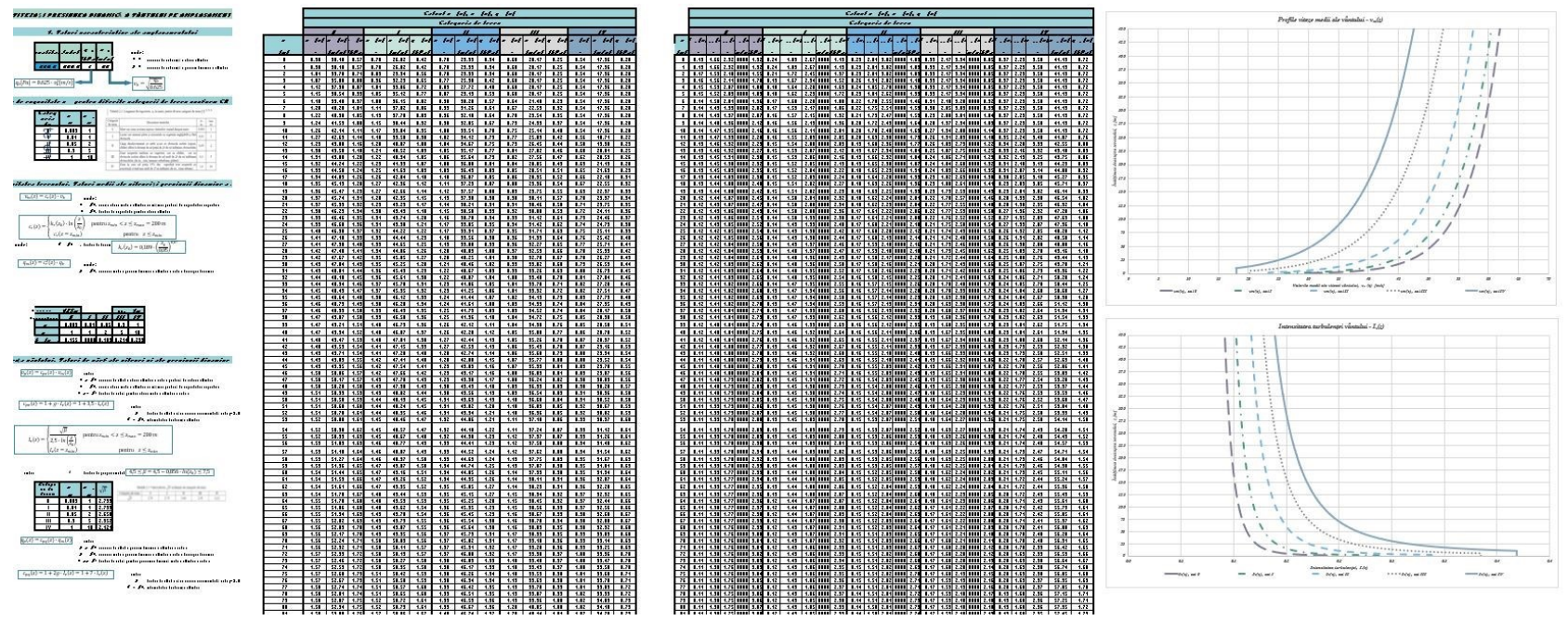

Fig. 6. Capture of the newly created Excel spreadsheet for the computation of the mean wind speed and turbulence intensity profiles

\section{Results and discussions}

To achieve our goal, we have created a spreadsheet solution in Excel [22].

Thus, by using the equation (1) and considering the dynamic wind pressure reference values for each county in Romania (see Fig. 1), we were able to obtain the map for Romania for the reference value of the wind speed for each different county, in part. Fig. 7 shows the zoning map of the reference value of the wind speed for Romania. Based on a brief analysis of Fig. 7, it can be said that on the territory of Romania, the reference value of the wind speed has values between $25.30 \mathrm{~m} / \mathrm{s}$ and $33.47 \mathrm{~m} / \mathrm{s}$.

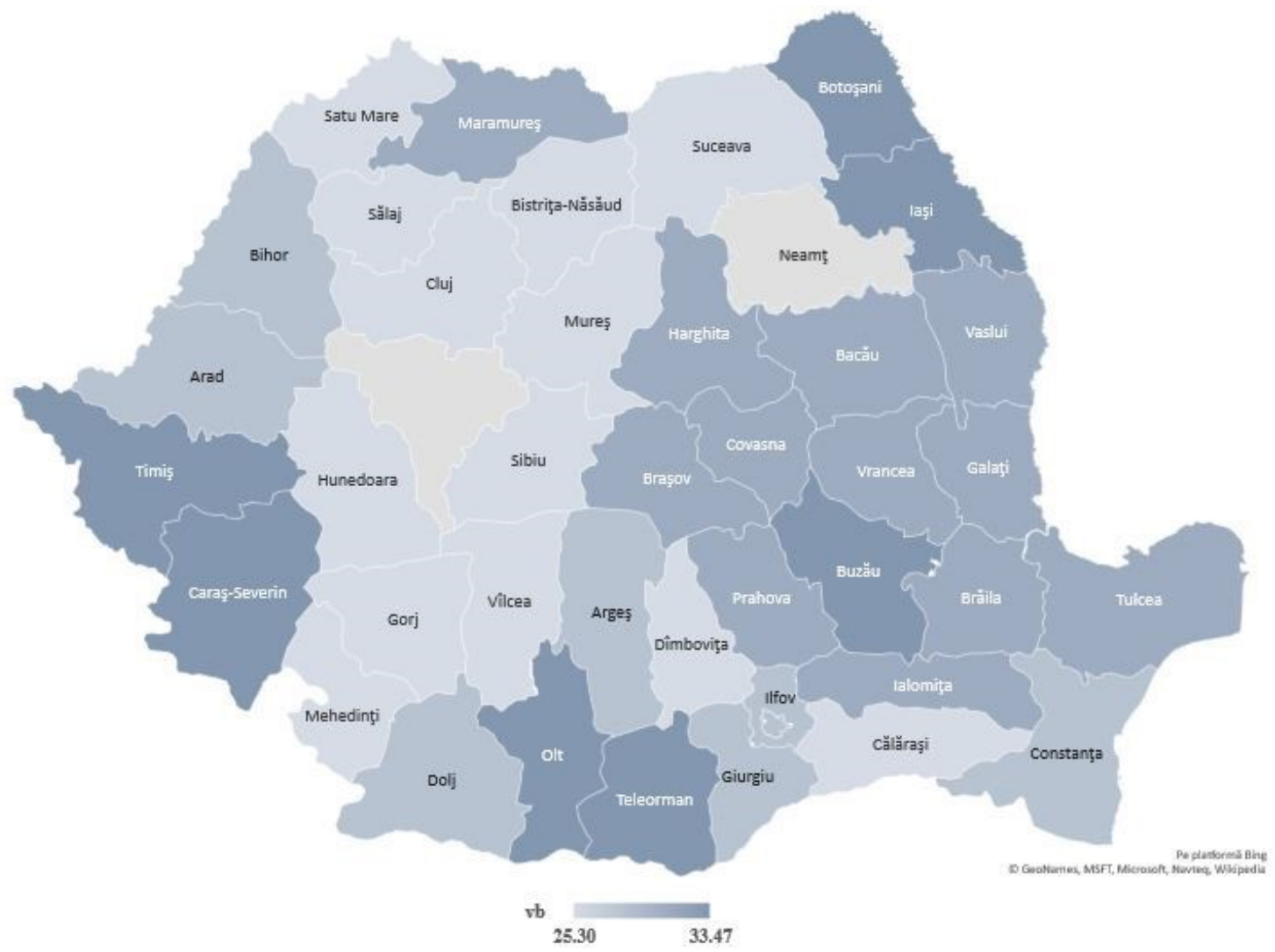

Fig. 7. The zoning map of Romania with the specific wind speed reference value for each county. 
The next step for the calculation sheet was to determine the mean wind speed profiles (see equation (2)) and the turbulence intensity profiles (see equation (7)) for each county in Romania. To exemplify the above-mentioned procedures (see Fig. 2, Fig. 3, Fig. 4 and Fig. 5) and to have a clear image on the important results that this spreadsheet provides, we have chosen two different areas from the Romania's territory. The two locations in Romania were not randomly chosen. These locations generally have at least an area that is characterized by a different category of terrain among the five described in the Romanian design standard for wind action [7] (see Table 1). The first chosen location was Buzău county and the second one was Constanța county.

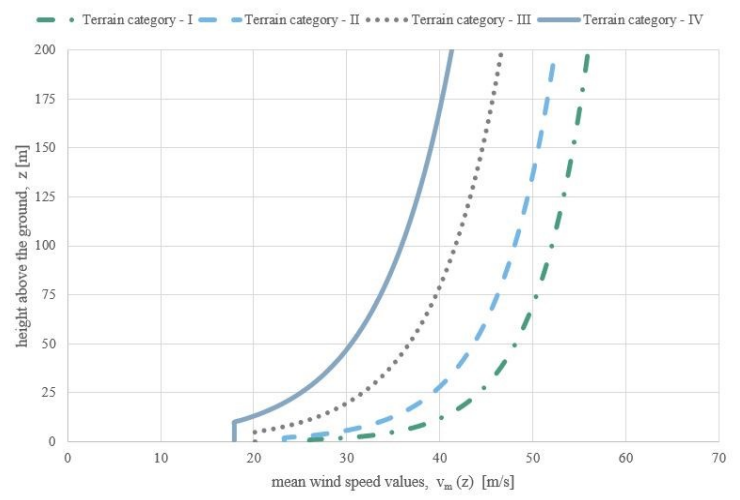

Fig. 8. Mean wind speed profiles for Buzău county.

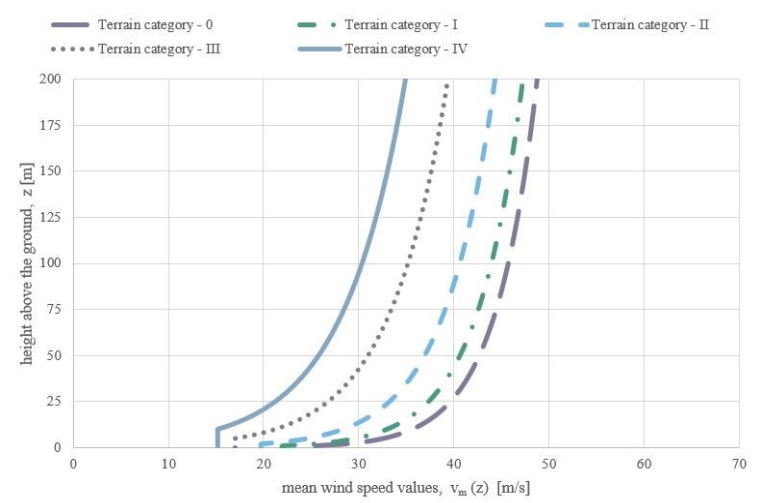

Fig. 9. Mean wind speed profiles for Constanța county.

According to CR 1-1-4/2012, the Buzău county is characterized by a dynamic pressure equal to $0,7 \mathrm{kPa}$ (see Fig. 1), and we obtained a reference value of the wind speed equal to $33,47 \mathrm{~m} / \mathrm{s}$ (see Figure 6). This location has areas which are placed on the I, II, III and IV categories with respect to the types of the terrain roughness described in the code [7]. As for the Constanța county, the value of the dynamic pressure is equal to 0,5 $\mathrm{kPa}$ and by computing the reference value of the wind speed with equation (1) the value of it was equal to 28,28 $\mathrm{m} / \mathrm{s}$ (see Fig. 6). Regarding the specific terrain types for this city, Constanța has areas for all five types of terrain categories described in CR 1-1-4/2012 (see Table 1) [7].

Considering the wind speed reference values for Buzău and Constanța counties (see Fig. 7), and by applying the above exemplified algorithms, we were able to determine both mean wind speed and turbulence intensity profiles.

Fig. 8 shows the mean speed profiles obtained for Buzău. These profiles are specific to each type of terrain that this site has. The differences between the four mean speed profiles are due to the variable roughness length that characterizes each category of terrain, $z_{0}$, (see Table 1) [7].

In Fig. 9 are plotted the five different mean wind speed profiles for Constanţa. Also, the differences between the profiles are because each type of terrain category is characterized by another variable length of roughness, $z_{0}[7]$.

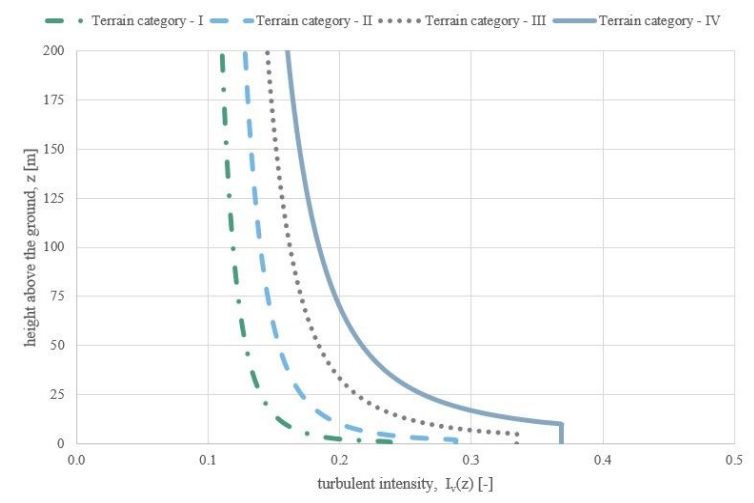

Fig. 10. Turbulence intensity profiles for Buzău county.

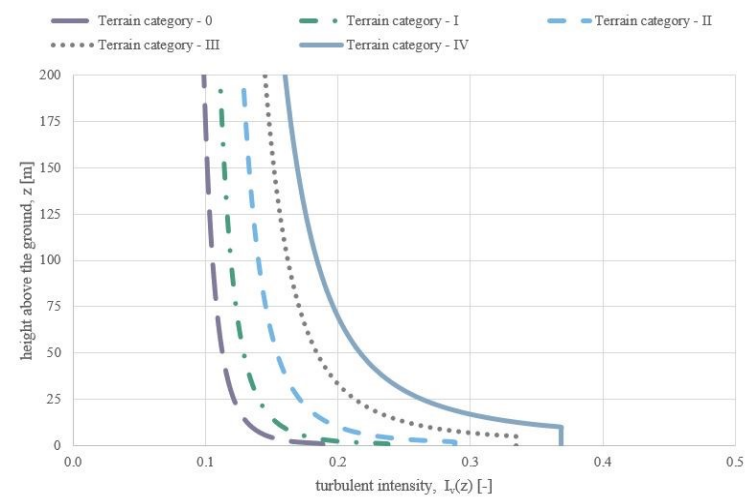

Fig. 11. Turbulence intensity profiles for Constanța county.

Also, with the help of the especially designed spreadsheet we could also obtain the turbulence intensity profiles for Buzău, see Fig. 10. The difference between these profiles is due to the length of roughness, $z_{0}$, that influences the proportionality factor, $\sqrt{\beta}$ (see Table 3 ) [7].

For Constanta, five different profiles of turbulent intensity were obtained (see Fig. 11). The profiles thus obtained different due to the length of roughness, $z_{0}$, that characterizes each category of land [7].

Since the Romanian standard provides the reference values of the dynamic wind pressure for 337 urban counties in Romania, by using the newly created spreadsheet we have achieved the mean wind speed and 
turbulent intensity profiles for all areas specific to these locations.

\section{Concluding remarks}

By realizing this spreadsheet solution, the mean wind speed and the turbulence intensity profiles were computed in accordance with the Romanian standard for wind action, CR 1-1-4/2012 [21]. The obtained results were for all the counties in Romania country.

This Excel [22] spreadsheet can be of real use to both civil engineering students and structural designers. Due to the information this spreadsheet provides, both target categories will know exactly how is characterized the atmospheric boundary layer of the site (in terms of mean wind speed and turbulent intensity profiles) on which they are going to do a study for a building or to another problem related to wind action.

Our future research will focus on improving this spreadsheet by adding the mathematical support from CR 1-1-4/2012 to determine the power spectrum of wind for a specific height. Also, the data thus obtained will be specific for Romania.

\section{References}

1. E. K. Bandi, Y. Tamura, A. Yoshida, Y. C. Kim, and Q. Yang, Experimental investigation on aerodynamic characteristic of various triangularsection high-rise buildings, J. W. Eng. Ind. Aer., 122, 60-68, (2013) https://doi.org/10.1016/j.jweia.2013.07.002

2. E. A. Chiulan, I. Popa, and A. Anton, Experimental study on an aeroelastic model of a television tower in the boundary layer wind tunnel, Bul. Trans. Univ. Brasov, $10 \quad$ (2), 7-18, $\quad$ (2017) http://rs.unitbv.ro/Bulletin/Series\%20I/2017/BULE TIN\%20I/Chiulan_E.A.pdf

3. E. A. Chiulan I. Popa, A. C. Vlăduţ, C. I. Coșoiu, A. M. Georgescu, A. Anton and M. Degeratu, Experimental investigation on the behavior of a tall and slender building placed in a turbulent boundary layer, IEEE Conf. Publications, 2017 Int. Conf. on Energy and Environment CIEM (2017) https://ieeexplore.ieee.org/document/8120792

4. R. O. Denoon, and K. C. S. Kwok, Fullscale measurements of wind-induced response of a $84 \mathrm{~m}$ high concrete control tower, J. W. Eng. Ind. Aer., 60, 155-165 (1996) https://doi.org/10.1016/01676105(96)00030-X

5. J. Y. Fu, J. R. Wu, A. Xu, Q. S. Li, and Y. Q. Xiao, Full-scale measurements of wind effects on Guangzhou West Tower, Eng. Struct., 35, 725-739 (1998) https://doi.org/10.1016/j.engstruct.2011.10.022

6. A. Kareem, S. Kabat and F. L. Haan Jr., Aerodynamics of Nanjing Tower: A case study, J. W. Eng. Ind. Aer., 77-78, 60-68 (2013) https://doi.org/10.1016/S0167-6105(98)00187-1
7. P. A. Irwin, Wind-engineering challenges of the new generation of super-tall buildings, J. W. Eng. Ind. Aer., 97, 328-334 (2009) https://doi.org/10.1016/j.jweia.2009.05.001

8. F. A. Johann, E. N. M. Mazzilli, and F. L. S. Ricardo, Wind-induced motion on tall buildings, J. W. Eng. Ind. Aer., 142, 26-42 (2015) https://doi.org/10.1016/j.jweia.2015.03.001

9. Q. S. Li, Y. Q. Xiao, J. Y. Fu, and Z. N. Li, Fullscale measurements of wind effects on the Jin Mao Building, J. W. Eng. Ind. Aer., 95, 445-466 (2007) https://doi.org/10.1016/j.jweia.2006.09.002

10. A. M. Marra, C. Mannini, and G. Bartoli, Measurements and improved model of vortexinduced vibration for an elongated rectangular cylinder, J. W. Eng. Ind. Aer., 147, 358-367 (2015) https://doi.org/10.1016/j.jweia.2015.08.007

11. L. Rosa, G. Tomasini, A. Zasso, and A.M. Aly, Wind-induced dynamics and loads in prismatic slender building: A modal approach based on unsteady pressure measurements, J. W. Eng. Ind. Aer., 107-108, 118-130 (2012) https://doi.org/10.1016/j.jweia.2012.03.034

12. H. Tanaka, Y. Tamura, K. Ohtake, M. Nakai, and Y. C. Kim, Experimental investigation of aerodynamic forces and wind pressures acting on tall building with various unconventional configurations, J. W. Eng. Ind. Aer., 107-108, 179-191 (2012) https://doi.org/10.1016/j.jweia.2012.04.014

13. J. Xie, Aerodynamic optimization of super-tall buildings and its effectiveness assessment, J. W. Eng. Ind. Aer., 130, 88-98 (2014) https://doi.org/10.1016/j.jweia.2014.04.004

14. A. M. Georgescu, C. Iamandi, and M. Degeratu, $A$ wind tunnel study for a TV tower in BucharestRomania, Proc. 1996 Urban Engineering in Asian Cities in Asian Cities in the $21^{\text {st }}$ Cent., Bangkok, 1, 315-320 https://www.researchgate.net/publication/28326785 5 A_WIND TUNNEL_STUDY_FOR_A_TV_TO WER_IN_BÜCHAREST-_ROMANIA

15. ***, ASCE-7 02: Minimum Design Loads for Buildings and Other Structures (1993) https://law.resource.org/pub/us/cfr/ibr/003/asce.7.20 02.pdf

16. ***, EN 1991-1-4, Eurocode 1: Actions on structures - Part 1-4: General actions - Wind actions (1991) https://www.phd.eng.br/wpcontent/uploads/2015/12/en.1991.1.4.2005.pdf

17. ***, AS/NZS 1170.2: 2011 - Structural design actions - Part 2: Wind actions (2011) https://vicparks.com.au/app/uploads/2016/02/AS_N ZS 1170.2-2002_Structural_design_actions Wind_actions.pdf

18. ***, Code of Practice on Wind Effects in Hong Kong

https://www.bd.gov.hk/english/documents/code/win dcode2004.pdf 
19. ***, AIJ Recommendations for Loads on Buildings (2004) http://www.wind.arch.tkougei.ac.jp/info_center/ITcontent/tamura/6.pdf

20. ***, KGG - KBCS - 13: Wind Load of Standard Design Loads for Buildings (2013) http://www.wind.arch.tkougei.ac.jp/APECWW/Report/2010/CHN.pdf

21. ***, CR 1-1-4/2012, Design code. Evaluation of wind action on constructions (trans. Cod de proiectare. Evaluarea actiunii vantului asupra constructiilor) (2012) http://ugir.ro/wpcontent/uploads/2012/06/CR-1-1-4-2012.pdf

22. ***, Microsoft Office Support (2018) https://support.office.com/en-us/excel 